\title{
In-vitro Biodegradation of Micro-Arc Oxidation on AZ31 Hybridized with Dopamine Compared to Phytic Acid
}

ISSN: 2576-8840

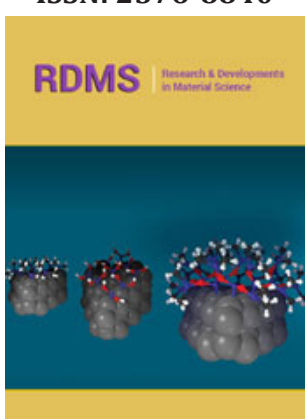

*Corresponding author: Hanaa Soliman, Central Metallurgical Research and Development Institute, Cairo, Egypt

Submission: 非 April 13, 2020

Published: 睑 May 11, 2020

Volume 13 - Issue 2

How to cite this article: Hanaa Soliman, Sun Mingyao, Guojiang Wan. In-vitro Biodegradation of Micro-Arc Oxidation on AZ31 Hybridized with Dopamine Compared to Phytic Acid. Res Dev Material Sci. 13(2). RDMS.000809. 2020.

DOI: $10.31031 /$ RDMS.2020.13.000809

Copyright@ Hanaa Soliman, This article is distributed under the terms of the Creative Commons Attribution 4.0 International License, which permits unrestricted use and redistribution provided that the original author and source are credited.

\author{
Hanaa Soliman ${ }^{1,2 *}$, Sun Mingyao ${ }^{2}$ and Guojiang Wan ${ }^{2}$ \\ ${ }^{1}$ Central Metallurgical Research and Development Institute, Egypt \\ ${ }^{2}$ College of Materials Science and Engineering, Southwest Jiaotong University, China
}

\begin{abstract}
Hybrid coatings composed of the inorganic film; Micro-Arc Oxidized (MAO) and organic film; Dopamine (DOP) or Phytic Acid (PA) was successfully deposited on AZ31. The DOP@MAO@AZ31 film reduced the corrosion current 3-times the MAO film while, the PA@MAO@AZ31presented a slight improvement. Here, the film morphology is the master key for the corrosion resistance enhancement in Simulated Body Fluid (SBF). The Dopamine film supported the MAO inner layer and blocked the porous structure. The Phytic acid transformed the porous MAO layer into a cracked structure to facilitate corrosive ions attack. All experimental outcomes were verified by Scanning Electron Microscope (SEM), Fourier Transform Infrared Spectroscopy (FTIR) and X-ray Diffraction (XRD). The in-vitro corrosion performance was estimated utilizing electrochemical measurements.
\end{abstract}

Keywords: Micro-arc oxidation; Corrosion resistance; Hybrid coating; Mg

Graphical abstract

(Figure 1)

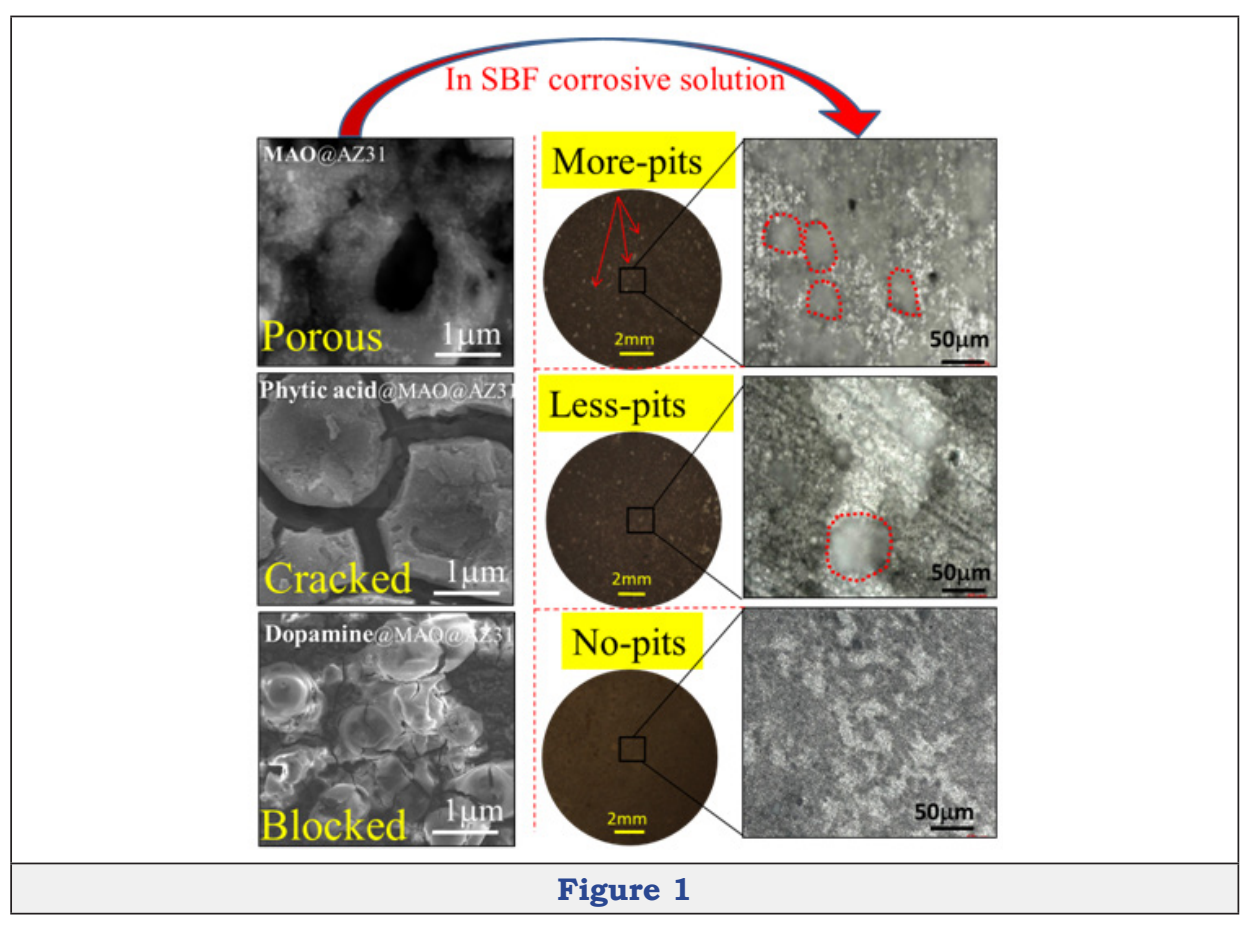

\section{Introduction}

More and more attention has been paid to magnesium alloys as a new generation of medical implant materials [1]. Mg alloys present physical and mechanical properties compatible with those of human bone however, the major obstacle for their use is the undesirable high corrosion rate [1]. This problem encourages the search for a protective coating to expand the use of Mg alloys. Currently, surface modification such as plasma electrolytic process (PEO) [2] 
or familiar as Micro-Arc Oxidation (MAO) is an effective method for improving their corrosion resistance [3-5].

Micro arc oxidation is sparked-anodization method where a high-voltage is used for the surface treatment of magnesium and its alloys. It consists of three layers; outer porous layer, the middle-fairly compact layer and the inner-compact layer sticking to the surfaces $[6,7]$. Thus, MAO process usually deposits a micronano scale porous bio ceramic layer on substrates [8] that allows a corrosive medium to move quickly into the substrate. Coupled with another technique [9] is a suitable solution for more protection such as dipping coating. Taking account of the fact that immersion the MAO films in the appropriate additive as post-treatment is valuable in inhibiting the corrosive ions.

Dopamine (DA) is a common adhesive material that serves as an antibacterial film for biomedical applications [8]. It is 3, 4-dihydroxyphenethylamine which is a natural hormone with a fundamental role in the brain and body. It is made of the catecholamine and phenethyl amine families consequently consists of a catechol structure (a benzene ring with two hydroxyl side groups) with one amine group attached via an ethyl chain. This structure qualify it to chelate with surface as a protective coating with bioactivity characters $[10,11]$.

Phytic Acid (PA) is a non-toxic organic compound with 12 hydroxyl groups to provide a powerful capability of chelating with $\mathrm{Mg}$ substrate. When PA hybridized with Silane compound on MAO film, an excellent barrier effect was obtained [12]. The purpose of the present work is to compare the hybrid coatings of DOP@MAO@ AZ31 and PA@MAO@AZ31 to the singleMAO@AZ31coating under the same conditions of electrolytes.

\section{Experimental Procedure}

\section{MAO coating preparation}

AZ31 magnesium was provided from Xinxiang Jiuli magnesium Co., Ltd. (Xinxiang, China) with nominal compositions wt.\%: 2.5-3.5 Al, 0.6-1.3 Zn, 0.1 Si, 0.04 Ca, 0.2-0.8 Mn, 0.05 Cu and balanced Mg. The samples were cut with a thickness of $1.5 \mathrm{~mm}$ and a diameter of $30 \mathrm{~mm}$ then, ground with silicon carbide sandpaper up to 2000 grit. Those samples were ultrasonically cleaned 5-10 s in alcohol and distilled water to let dry in air. Then, immersed in $\mathrm{Na}_{2} \mathrm{SiO}_{3}$ $9 \mathrm{H}_{2} \mathrm{O} 0.04 \mathrm{M}$ and $\mathrm{Na}_{3} \mathrm{PO}_{4} 12 \mathrm{H}_{2} \mathrm{O} 0.04 \mathrm{M}$ for 3 minutes with $200 \mathrm{~V}$ using $1 \mathrm{~kW}$ AC power supply with a duty cycle of $10 \%$.to get MAO $@ A Z 31$. Those samples were dried and immersed in Phytic acid $\left(\mathrm{CH}_{3}\left(\mathrm{CH}_{2}\right)_{16} \mathrm{COOH}\right) 0.25 \mathrm{M} 4 \mathrm{~h}, 60^{\circ} \mathrm{C}$ to yield PA@MAO@AZ31 or in dopamine solution $\left(\mathrm{C}_{8} \mathrm{H}_{11} \mathrm{NO}_{2}\right)$ 0.25M 12h, pH 9 to get DOP@MAO@ AZ31. Finally, those specimens were washed with distilled water three times and dried in the air prior to characterization.

\section{Coating characterization}

The optical macroscope and scanning electron microscopy (SEM, JSM-7401F JEOL, Japan) were utilized to observe the surface morphologies of the prepared samples. The electron beam of SEM is $0.8 \mathrm{~nm}$ at $15 \mathrm{kV}$ under a pressure of $4.45-10.4 \mathrm{~Pa}$. A very thin layer of gold must be sputtered to the samples before the SEM observations.
A goniometer (DSA100, Kru€uss, Hamburg, Germany) at $25^{\circ} \mathrm{C}$ and $60 \%$ relative humidity was utilized to record the water contact angle for the coated samples in static drop mode. For each sample, at least five measurements on random surface sites were tested.

Fourier transform infrared spectroscopy (FTIR, Nicolet 5700, Thermo Electron Corporation, MA, USA) was utilized to characterize the functional-groups within the coatings (organic film). The scanning rates from 500 to $4000 \mathrm{~cm}^{-1}$, then the data are converted into absorbance spectra. For further more exposure (inorganic film), the phases structures of the samples were characterized by X-ray diffraction (XRD, Philips X'Pert) using a CuK radiation with a glancing angle of $2^{\circ}$. The XRD data were obtained over $2 \theta$ range of $20-40^{\circ}$ at a step size of $0.25^{\circ}$.

\section{Electrochemical corrosion behavior}

Potentiostat (IM6, Zahner, Germany) was used to test potentiodynamic polarization (PDP) and Electrochemical Impedance Spectroscopy (EIS). The corrosive electrolyte was the fresh-prepared Simulated Body Fluid (SBF) with similar ionic composition to that of human blood plasma. It contains $8.8 \mathrm{~g} / \mathrm{l} \mathrm{NaCl}$, $0.4 \mathrm{~g} / \mathrm{l} \mathrm{KCl}, 0.14 \mathrm{~g} / \mathrm{l} \mathrm{CaCl}_{2}, 0.35 \mathrm{~g} / \mathrm{l} \mathrm{NaHCO}_{3}, 1.0 \mathrm{~g} / \mathrm{l} \mathrm{C}_{6} \mathrm{H}_{6} \mathrm{O}_{6}$ (glucose), $0.2 \mathrm{~g} / \mathrm{l} \mathrm{MgSO}{ }_{4} 7 \mathrm{H}_{2} \mathrm{O}, 0.1 \mathrm{~g} / \mathrm{l} \mathrm{KH}_{2} \mathrm{PO}_{4} \cdot \mathrm{H}_{2} \mathrm{O}, 0.06 \mathrm{~g} / \mathrm{l} \mathrm{Na}_{2} \mathrm{HPO}_{4} \cdot 7 \mathrm{H}_{2} \mathrm{O}, \mathrm{pH}$ 7.4 , at a temperature of $37^{\circ} \mathrm{C}$. A three-electrode cell consists of platinum foil $(1 \mathrm{~cm} 2)$ as a counter electrode, saturated calomel (SCE, Lei Ci 232, Shang Hai, China) as reference one and the samples of an area of $0.79 \mathrm{~cm}^{2}$ were the working electrodes.

The PDP curves were obtained by scanning the electrode potential from -2.0 to $-1.0 \mathrm{~V}_{\text {SCE }}$ at a scanning rate of $1 \mathrm{mV} \mathrm{s}^{-1}$. The polarization plots were analyzed by linear extrapolation to detect cathodic Tafel slope and specify the values of free corrosion potentials $\mathrm{E}_{\text {corr }}$, corrosion current density $\mathrm{i}_{\text {corr }}$. The taken region for data calculation was about $50 \mathrm{mV}$ more negative than the free corrosion potential. The EIS spectrum was obtained at the fixed DC potential when the stabilization stopped. The excitation signal of a sinusoidal alternating voltage $10 \mathrm{mV}$ was superimposed on the DC potential, which was scanned from $200 \mathrm{kHz}$ to $0.01 \mathrm{~Hz}$. The acquired EIS data were recorded using the Zsim Demo software.

\section{Results and Discussion}

\section{Coating morphology and wettability}

The optical microscope, scanning electron microscope and water contact angle are illustrated in Figure 2. MAO@AZ31 film presented porous structure that transformed into cracked morphology atPA@MAO@AZ31 films. The disappearance of the porous structure could be attributed to the ability of Phytic acid to attack the surface [13]. On the contrary, the DOP@MAO@AZ31 film revealed agglomerated particles of dopamine that blocked the porous MAO structure. Dopamine caneffuse through the discharge channels and quenched to yield a compact layer [8], consequently,a thick film of $19 \mu \mathrm{m}$ is formed. The water contact angle (WCA) of bothMAO@AZ31 and PA@MAO@AZ31 films presented hydrophilic behavior that could be related to their morphology. On the other hand, DOP@MAO@AZ31 coating was hydrophobic with water contact angle $112^{\circ} \mathrm{C}$. 


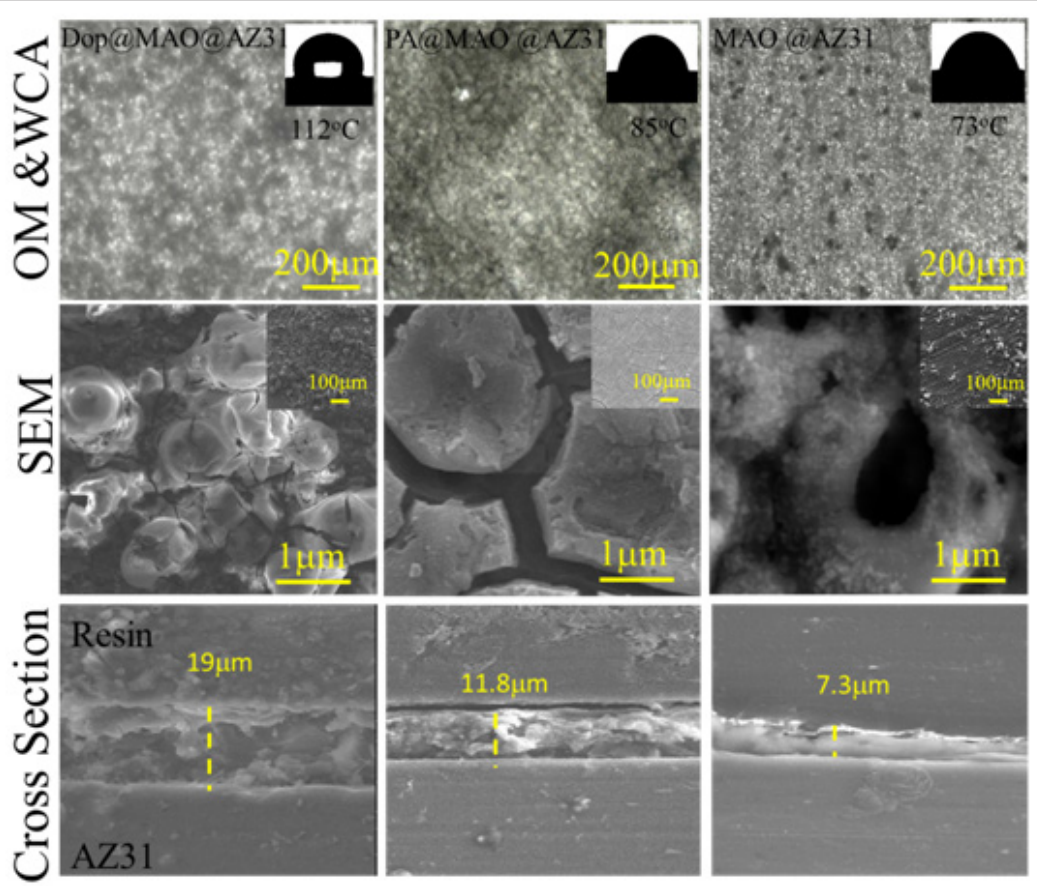

Figure 2: Opical microscopy, scanning electron microscope and water contact angle of MAO@AZ31, PA@MAO@AZ31 and DOP@MAO@AZ31 composite coatings.

\section{XRD \&FTIR}

The composition of the surface coating was analyzed using the XRD patterns in Figure 3a. The XRD pattern detected the phases of the micro-arc oxidized film MAO@AZ31, PA@MAO@AZ31 andDOP@MAO@AZ31. The main phase that can be seen is $\mathrm{Mg}_{2} \mathrm{SiO}_{4}$ mixed with NaMgPO4. The weakest intensity of $\mathrm{Mg}_{2} \mathrm{SiO}_{4}$ peak appeared at DOP@MAO@AZ31as due to the presence of the second layer covers well MAO film. FTIR spectra Figure 3b illustrated the peaks that rely on organic function groups. The PA@MAO@AZ31 film revealed $\mathrm{OH}$ stretched and bonded groups at $3600 \mathrm{~cm}^{-1}$ and $2500 \mathrm{~cm}^{-1}$, respectively [12] as an indication of the organic Phytic acid. The DOP@MAO@AZ31 film presented the amine peak at $2150 \mathrm{~cm}^{-1}$ [8] to prove the organic dopamine deposition. Both of those analyses confirmed the successful hybridization between the inorganic silicate $\left(\mathrm{Mg}_{2} \mathrm{SiO}_{4}\right)$ with the organic film such as dopamine or Phytic.
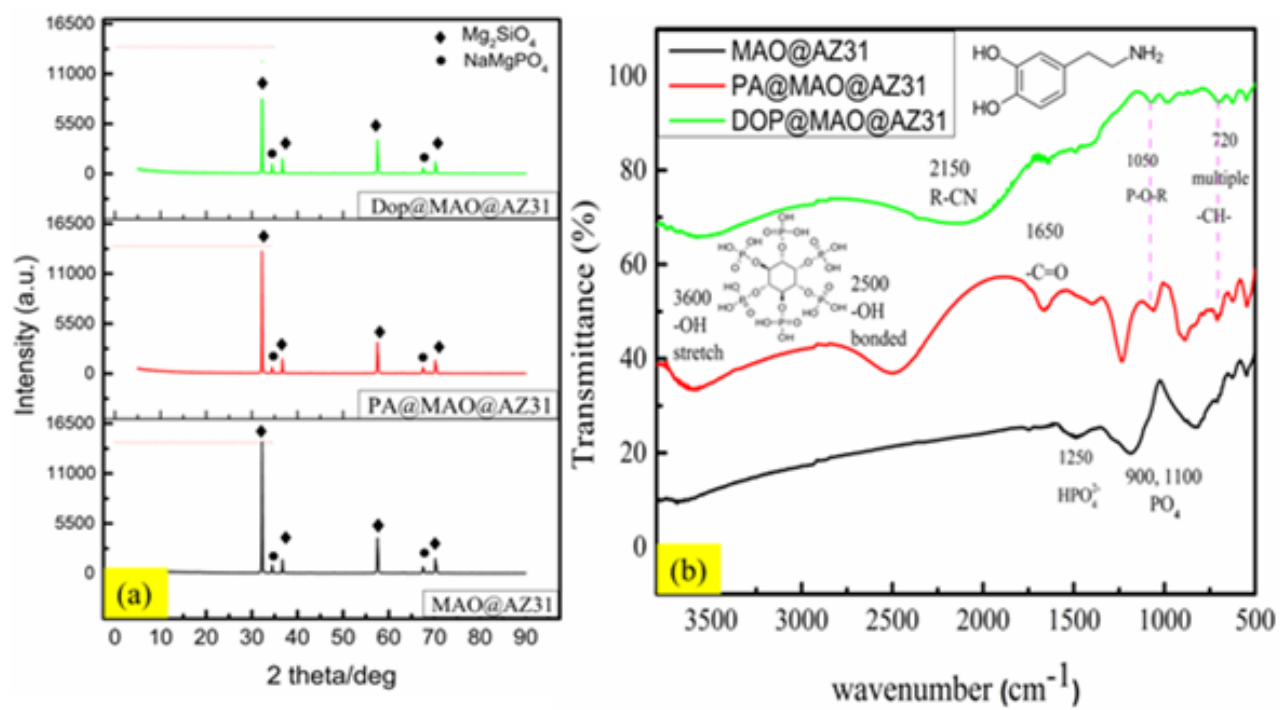

Figure 3: XRD and FTIR sprctra of MAO@AZ31, PA@MAO@AZ31 and DOP@MAO@AZ31 composite coatings.

\section{Corrosion behavior}

The electrochemical potentiodynamic curves, Nyquist plots and optical microscope for the corroded film are illustrated in
Figure 4. The Phytic Acid (PA) presented a slight shift in the potential accompanied by passive current (Figure 4a). This result is an indication that cracked structure (PA@MA0@AZ31) yielded no clear difference than the porous structure (MAO@AZ31). On 
the other side, the agglomerated dopamine confirmed the barrier property due to more noble corrosion potential and less value of passive current (Table 1). The corrosion current of DOP@MAO@
AZ31was reduced 3-times the MAO single-film. The Nyquist plots supported the PDP curves because the obvious jump in the resistance belongs to the DOP@MAO@AZ31 film.
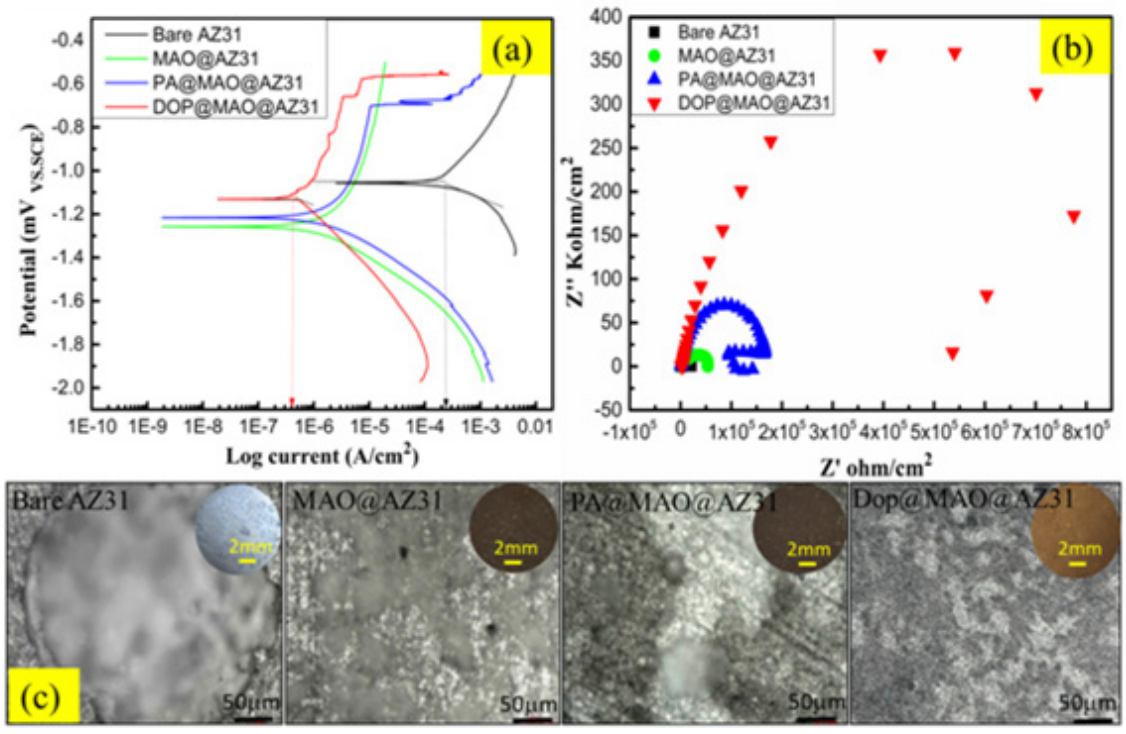

Figure 4: Potentiodynamic, Nyquist curves and OM for the corroded films ofMAO@AZ31, PA@MAO@AZ31 and DOP@ MAO@AZ31in SBF.

Table 1: Electrochemical parameters for MAO@AZ31, PA@MAO@AZ31 and DOP@MAO@AZ31compared to Bare AZ31.

\begin{tabular}{|c|c|c|c|c|}
\hline Samples & BareAZ31 & $\begin{array}{c}\text { MA0@ } \\
\text { AZ31 }\end{array}$ & $\begin{array}{c}\text { PA@MA0@ } \\
\text { AZ31 }\end{array}$ & $\begin{array}{c}\text { DOP@MAO@ } \\
\text { AZ31 }\end{array}$ \\
\hline Ecorr $(\mathrm{VSCE})$ & -1.05 & -1.3 & -1.22 & -1.13 \\
\hline I corr $\left(\mu \mathrm{A} / \mathrm{cm}^{2}\right)$ & 250 & 1.1 & 0.9 & 0.4 \\
\hline C.R $(\mathrm{mpy})$ & 224 & 2.9 & 2.3 & 0.35 \\
\hline
\end{tabular}

The assumed mechanism in case of dopamine which has a higher tendency to agglomerate [14], yielded a greater thickness. This polydopamine (PDOP) second layer can cover wellthe first layer of silicate, lowers the intensity of $\mathrm{Mg}_{2} \mathrm{SiO}_{4}$ (XRD). Hence, this double-layer can successfully isolate AZ31 from the corrosive ions, reduce the corrosion rate.

In case, Phytic acid dissolves the first silicate layer according to the following equation [15],

$$
\mathrm{Mg}_{2} \mathrm{SiO}_{4}+\left[\mathrm{H}_{6}\right]^{+}[\mathrm{PA}]^{6-} \rightarrow \mathrm{SiO}_{2}+\mathrm{H} 2 \mathrm{O}+\left[\mathrm{Mg}_{2}\right]^{3+}[\mathrm{PA}]^{6-}
$$

This acid caused a cracked film (SEM) upon AZ31, facilitated the attack of corrosive ions. Therefore that cracked structure(PA@ MA0@AZ31) presented non-remarked enhancement that the porous structure (MAO@AZ31).

\section{Conclusion}

Acombination of organic film overlays MAO cant for sure provides surface protection. If the organic film such as phytic acid attacked the MAO film, a slight enhancementis obtained. The porous MAO structure when transformed into a cracked one, facilitated the corrosive ions penetration. If the organic film such as dopamine supported the MAO film to effectively isolate the AZ31, a significant improvement is obtained. The dopamine reduced the corrosion current 3 times the MAO@AZ31due to dopamine agglomeration thatblockedthe porous structure.

\section{References}

1. Cui XJ, Li MT, Yang RS, Yu ZX (2016) Structure and properties of a duplex coating combining micro-arc oxidation and baking layer on AZ91D Mg alloy. Applied Surface Science 363: 91-100.

2. Ding ZY, Wang YH, Ouyang JH, Liu ZG, Wang YM, et al. (2018) Insights into structure and high-temperature oxidation behavior of plasma electrolytic oxidation ceramic coatings formed in $\mathrm{NaAlO}_{2}-\mathrm{Na}_{2} \mathrm{CrO}_{4}$ electrolyte. Journal of Materials Science 53 (14): 9978-9987.

3. Al-Zoubi W, Min JH, Ko YG (2017) Hybrid organic-inorganic coatings via electron transfer behaviour. Scientific Reports 7 (1): 7063.

4. Tran QP, Kuo YC, Sun JK, He JL, Chin TS (2016) High quality oxide-layers on Al-alloy by micro-arc oxidation using hybrid voltages. Surface and Coatings Technology 303: 61-67.

5. Dehghanghadikolaei A, Ibrahim H, Amerinatanzi A, Hashemi M, Moghaddam NS, et al. (2019) Improving corrosion resistance of additively manufactured nickel-titanium biomedical devices by microarc oxidation process. Journal of Materials Science 54(9): 7333-7355.

6. Darband GB, Aliofkhazraei M, Hamghalam P, Valizade N (2017) Plasma electrolytic oxidation of magnesium and its alloys: Mechanism, properties and applications. Journal of Magnesium and Alloys 5 (1): 74132.

7. Aktug SL, Durdu S, Aktas S, Yalcin E, Usta M (2019) Surface and in vitro properties of Ag-deposited antibacterial and bioactive coatings on AZ31 Mg alloy. Surface and Coatings Technology 375: 46-53.

8. He Y, Zhang Y, Shen X, Tao B, Liu J, et al. (2018) The fabrication and in vitro properties of antibacterial polydopamine-LL-37-POPC coatings on micro-arc oxidized titanium. Colloids and Surfaces B: Biointerfaces 170: 54-63. 
9. Dou J, Yu H, Chen C (2019) Preparation and characterization of composite coating on Mg-1.74 Zn-0.55 Ca alloy by micro-arc oxidation combined with sol-gel method. Materials Letters 255: 126578.

10. Song C, Yang Y, Zhou Y, Wang L, Zhu S, et al. (2019) Electrochemical polymerization of dopamine with/without subsequent PLLA coating on Mg-Zn-Y-Nd alloy. Materials Letters 252: 202-206.

11. Lin B, Zhong M, Zheng C, Cao L, Wang D, et al. (2015) Preparation and characterization of dopamine-induced biomimetic hydroxyapatite coatings on the AZ31 magnesium alloy. Surface and Coatings Technology 281: 82-88.

12. Pak SN, Jiang Z, Yao Z, Ju JM, Ju KS, et al. (2017) Fabrication of environmentally friendly anti-corrosive composite coatings on AZ31B Mg alloy by plasma electrolytic oxidation and phytic acid/3- aminopropyltrimethoxysilane post treatment. Surface and Coatings Technology 325: 579-587.

13. Guo X, Du K, Guo Q, Wang Y, Wang R, Wang F, et al. (2013) Effect of phytic acid on the corrosion inhibition of composite film coated on Mg-Gd-Y alloy. Corrosion Science 76: 129-141.

14. Georgopanos P, Eichner E, Filiz V, Handge UA, Schneider GA, et al. (2017) Improvement of mechanical properties by a polydopamine interface in highly filled hierarchical composites of titanium dioxide particles and poly (vinyl butyral). Composites Science and Technology 146: 73-82.

15. Decleer J (2003) Exploratory research into new materials: Use of carbon residue in concrete applications and transformation of silicates into filling materials. Industrial Minerals: Resources, Characteristics, and Applications. 